\title{
Retraction Note to: Effect of Calcium and Silicate Application on Pathogenicity of Erwinia carotovora subsp. carotovora in Zantedeschia spp.
}

\author{
Hae Ryong $\mathrm{Cho}^{1} \cdot$ Hyang Young Joung ${ }^{1} \cdot \mathrm{Ki}-\mathrm{Byung} \mathrm{Lim}^{2} \cdot \mathrm{Ki}_{\text {Sun }} \mathrm{Kim}^{3}$
}

Published online: 8 February 2018

๑) Korean Society for Horticultural Science and Springer-Verlag GmbH Germany, part of Springer Nature 2018

\section{Retraction Note to: \\ Hort. Environ. Biotechnol. 54(4):364-371. 2013. https://doi.org/10.1007/s13580-013-0059-1}

The authors are retracting this article (Cho et al., 2013). After publication the authors became aware that the article contains errors in the reporting and interpretation of data, and consequently, the conclusions drawn are not valid. Hae Ryong Cho is deceased; all other authors agree with this retraction.

The original article can be found online at https://doi.org/10.1007/ s13580-013-0059-1.

Ki Sun Kim

kisun@snu.ac.kr

1 National Institute of Horticultural \& Herbal Science, Rural Development Administration, Suwon 441-440, Korea

2 Department of Horticultural Science, Kyungpook National University, Daegu 702-701, Korea

3 Department of Plant Science, Seoul National University, Seoul 151-921, Korea 